\title{
Neutrophil-to-Lymphocyte Ratio and Non-arteritic Anterior Ischemic Optic Neuropathy
}

\author{
Murat Afyon, Akın Çakır \\ Primary Care and Examination, Family Health Center and the Naval Academy Clinic, Gülhane Military Medical Academy Haydarpaşa Training Hospital, İstanbul, Turkey
}

Letter to the Editor,

In the recent issue of the Balkan Medical Journal, we read with interest the article by Polat et al. (1): "Neutrophil-toLymphocyte Ratio as a Marker in Patients with Non-arteritic Anterior Ischemic Optic Neuropathy". We wanted to specify some matters and our thoughts related to this article.

First of all, as mentioned in the article, neutrophil-to-lymphocyte ratio (NLR) can be affected in patients with systemic diseases and it is a shortcoming that the patients in this study were not evaluated for the existence of other systemic diseases except for diabetes mellitus and hypertension, while patients were excluded from study in the presence of heart disease, coronary artery disease, liver disease or malignancy. In addition, infections, even if localized, can affect neutrophil count, lymphocyte count and therefore NLR (2). It has been reported that NLR is a more powerful predictor of infection than simple white blood cell counts (3). As a result, patients, both in the study group and the control group, should be evaluated for the presence of any infection in the period of laboratory testing aside from systemic diseases. We think that this is another drawback of this study resulting from retrospective analysis.

Secondly, we believe that selecting a control group containing only cataract patients was another drawback which might have affected the results. Although to the best of our knowledge there has been no study investigating the association between cataracts or the etiological causes and NLR, as a theory, cataracts or more likely the etiological causes resulting in cataracts might affect NLR. For this purpose, it would be better that age- and gender-matched individuals without cataracts, any infection or systemic disease and some patients with only diabetes mellitus and/or hypertension had been selected as control groups 1 and 2. This may also be another drawback resulting from the retrospective nature of the analysis.

Lastly, the authors mentioned that best corrected visual acuity (BCVA) at the time of diagnosis and in the third month was significantly and negatively correlated with NLR $(r=-0.406$, $\mathrm{p}=0.008 ; \mathrm{r}=-0.408, \mathrm{p}=0.028$, respectively). Due to this find- ing, they discussed whether NLR may be a predictive factor or marker in the diagnosis of non-arteritic anterior ischemic optic neuropathy. However, when interpreting the results in Spearman correlation analysis, the ' $r$ ' value must be considered. As a result, in this study there was a statistically significant but moderate correlation between BCVA and NLR.

\section{Ethics Committee Approval: N/A.}

\section{Informed Consent: N/A.}

Peer-review: Externally peer-reviewed.

Author contributions: Concept - M.A..; Design - M.A..; Supervision - M.A., A.Ç.; Resource M.A.; Materials - M.A.; Data Collection and/or Processing - M.A., A.Ç.; Analysis and/or Interpretation - M.A., A.Ç.; Literature Search M.A., A.Ç.; Writing - M.A.; Critical Reviews - M.A., A.Ç.

Conflict of Interest: No conflict of interest was declared by the authors.

Financial Disclosure: The authors declared that this study has received no financial support.

\section{REFERENCES}

1. Polat O, Yavaş GF, İnan S, Inan ÜÜ. Neutrophil-to-lymphocyte ratio as a marker in patients with non-arteritic anterior ischemic optic neuropathy. Balkan Med J 2015;32:382-7. [CrossRef]

2. Gürol G, Çiftçi İH, Terzi HA, Atasoy AR, Özbek A, Köroğlu M. Are there standadized cutoff values for neutrophil lymphocyte ratios in bacteremia or sepsis? J Microbiol Biotechnol 2015;25:521-5. [CrossRef]

3. Kwon JH, Jang JW, Kim YW, Lee SW, Nam SW, Jaegal D, et al. The usefulness of C-reactive protein and neutrophil-to-lymphocyte ratio for predicting the outcome in hospitalized patients with liver cirrhosis. BMC Gastroenterol 2015;15:146. [CrossRef] 


\section{AUTHORS' REPLY}

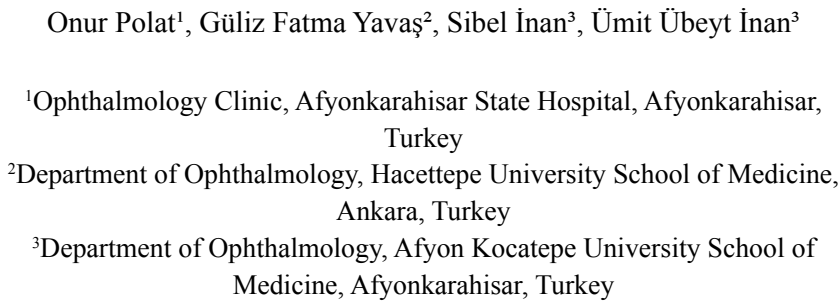

To the Editor,

We would like to thank the author(s) for their interest and letter to the editor regarding our article "Neutrophil-to-Lymphocyte Ratio as a Marker in Patients with Non-arteritic Anterior Ischemic Optic Neuropathy" (1).

As discussed in our article, neutrophil-to-lymphocyte ratio (NLR) can be affected in various diseases $(2,3)$. As the author(s) commented, the presence of any infection in the period of laboratory testing aside from systemic diseases should be evaluated (4). As stated in the discussion of our article, one drawback of our study was that it was performed retrospectively so we could not evaluate the existence of other systemic diseases; therefore, we concluded that prospective studies were needed. In their medical history, none of the subjects had a complaint of any infectious disease.

As mentioned by the author(s) and to the best of our knowledge, there has been no study investigating the association between cataracts and NLR. All of our subjects in the control group had senile cataracts. Ideally, a control group should be comprised of subjects with only mild refractive errors but without any other ocular disease. As the author(s) stated, one drawback of retrospective studies is that ideal groups cannot be generated. As our study was retrospective and we do not routinely perform laboratory testing in subjects with only mild refractive errors, we included subjects with senile cata- racts for whom laboratory testing is performed routinely. As stated above, cataracts is one of the ocular diseases which has not been reported to be related to NLR. Therefore, we do not believe that this is a drawback.

Lastly, when interpreting the results in Spearman correlation analysis, the ' $r$ ' value must be considered as well as the ' $p$ ' value; this is the reason why we included both ' $r$ ' and ' $p$ ' values. The correlation between the initial NLR and initial BCVA and initial NLR and BCVA at month 3 was statistically significant but moderate. This is consistent with our article.

In conclusion, further prospective studies are needed to evaluate NLR as a predictor for the assessment of visual acuity and prognosis in NAION.

We believe that we have answered the authors' concerns satisfactorily.

Address for Correspondence: Onur Polat, Ophthalmology Clinic, Afyonkarahisar State Hospital, Afyonkarahisar, Turkey

Phone: +905366156250 e-mail: dr_onurpolatt@hotmail.com

\section{REFERENCES}

1. Polat O, Yavas GF, Inan S, Inan UU. Neutrophil-to-lymphocyte ratio as a marker in patients with non-arteritic anterior ischemic optic neuropathy. Balk Med J 2015;32:382-7. [CrossRef]

2. Rudiger A, Burckhardt OA, Harpes P, Muller SA, Follath F. The relative lymphocyte count on hospital admission is a risk factor for long-term mortality in patients with acute heart failure. $\mathrm{Am} \mathrm{J}$ Emerg Med 2006;24:451-4. [CrossRef]

3. Walsh SR, Cook EJ, Goulder F, Justin TA, Keeling NJ. Neutrophil-lymphocyte ratio as a prognostic factor in colorectal cancer. J Surg Oncol 2005;91:181-4. [CrossRef]

4. Gürol G, Çiftçi IH, Terzi HA, Atasoy AR, Özbek A, Köroğlu M. Are there standardized cutoff values for neutrophil-lymphocyte ratios in bacteremia or sepsis? J Microbiol Biotechnol 2015;25:521-5. [CrossRef] 